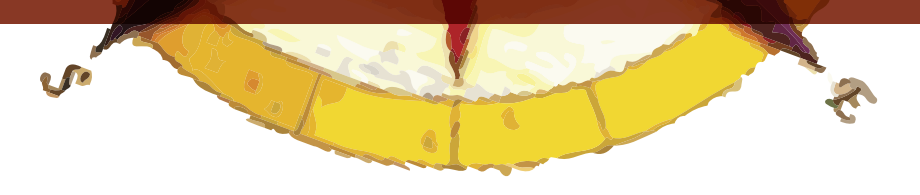

\title{
FORMACIÓN CIUDADANA, PROYECTOS POLÍTICOS Y TERRITORIO: PISTAS PARA LA ESCUELA
}

\author{
Alejandro Pimienta Betancur ${ }^{1}$
}

\section{RESUMEN}

Este artículo problematiza las relaciones conceptuales que se pueden establecer entre la formación ciudadana, el proyecto político y el territorio de manera que cimenten las bases teóricas para la formulación de problemas de investigación en campos diversos. Se enfatiza que en el centro de esas relaciones se encuentra lo que se denomina el sujeto político, es decir, el sujeto de la formación ciudadana, en cuyo proceso de constitución de su subjetividad política juega un rol central la educación formal y la enseñanza de la geografía.

Palabras Clave: Formación ciudadana, proyecto político, territorio, enseñanza de la geografía.

\section{RESUMO}

Este artículo problematiza as relações conceituais que possam estabelecer entre a formação cidadania, o projeto político e o território de maneira que cimentem as bases teóricas para a formulação do problema de investigação em campos diversos. Enfatiza-se que o centro de essas relações se encontra no que se denomina o sujeito político, ou seja, o sujeito da formação cidadania, em tal processo de constituição de sua subjetividade política joga um rol central a educação formal e o ensino da geografia.

Palavras chave: Formação cidadania, projeto político, território, ensino da geografia.

\section{INTRODUCCIÓN}

Esta artículo problematiza las relaciones conceptuales que se pueden establecer entre la formación ciudadana (FC), el proyecto político y el territorio de manera que cimenten las bases teóricas para la formulación de problemas de investigación en campos diversos. Se enfatiza que en el centro de esas relaciones se encuentra lo que se denomina el sujeto político, es decir, el sujeto de la formación ciudadana, en cuyo proceso de constitución de su subjetividad política, juega un rol central la

1 Investigador -Docente Instituto de Estudios Regionales INER Grupo GET (Grupo de Estudios del Territorio) Universidad de Antioquia Medellín - Colombia 
educación formal y la enseñanza de la geografía ${ }^{1}$.

\section{LA RELACIÓN DE LA FORMACIÓN CIUDADANA Y EL PROYECTO POLÍTICO: OTRA FORMA DE PENSAR EL TERRITORIO}

Los procesos de formación ciudadana, desarrollados como procesos de educación formal, no formal e informal, le otorgan sentido (fijación del significado) a los proyectos políticos y, a su vez, los proyectos políticos determinan en gran medida el discurso de los procesos de formación ciudadana. Así, los procesos de formación ciudadana, lejos de ser escenarios para la conciliación y el consenso con resultados ciertos, son campos en los que se pueden identificar desde intereses de ideologización e instrucción política hasta el debate abierto y la configuración de antagonismos, cuyos resultados, en términos de formación, son inciertos.

Este planteamiento es posible verificarlo desde la perspectiva analítica del Análisis Político del Discurso (APD), que se basa en un concepto de discurso apartado de la noción usada comúnmente que asocia el discurso a un acto del habla, entendido como un enunciado positivo que tiene una relación isomórfica con el significante y que puede corresponderse, o no, con un referente empírico. Este carácter isomórfico comúnmente asociado a la noción de discurso, implica que tiene una fijación permanente y definitiva, que permite a la gente definir su significado como verdad o mentira. Por el contrario, el discurso como concepto, tal como se abordó no tiene una fijación permanente y sobrepasa su referencia a un acto del habla, en tanto involucra lo lingüístico como lo extralingüístico.

Dicha analítica permite configurar un saber disperso, en este caso el de la formación ciudadana, como un discurso, que si bien tiene sedimentaciones de orden epistemológico, las desborda. Como estrategia metodológica, se aproxima a las perspectiva cualitativa pero no involucra un método propio sino, en correspondencia con el interés específico y la unidad analítica particular elegida, selecciona entre una caja de herramientas teóricas aquellas que sean apropiadas, siempre y cuando sean conceptualmente compatibles Buenfil (2006).

Desde esa perspectiva, emerge que la FC tiene una tensión inherente a partir de dos orientaciones. Una de ellas la relaciona, justamente, con los procesos de educación institucionalizada que deben darse no sólo, pero sí preferentemente en la institución escolar y más concretamente en los niveles básicos, en los cuales se asume a la formación como el resultado de la instrucción, la educación y el desarrollo en la institución escolar para un contexto específico como el latinoamericano que aunque demanda ir más allá de los moldes del republicanismo, el comunitarismo o el liberalismo plantea en cualquier caso la necesidad de un modelo que hay que alcanzar y que no todos alcanzarán, un modelo el que puedan confluir finalmente el ejercicio de la ciudadanía como práctica individual, social y colectiva. En esta orientación el énfasis está puesto en el proyecto político democrático, en el que por definición cabría la contingencia de la crítica frente al proyecto político imperante.

En la otra orientación el acento está puesto en el resultado. Esta no encuentra su sentido en la educación escolar sino precisamente en el discurso de la formación en cuanto tal, ya no sólo desde el discurso pedagógico, sino desde la filosofía (fenomenología), la sociología (Bourdieu) y la cien-

1 Este artículo hace parte de los resultados finales de la tesis doctoral en educación "Formación ciudadana, proyecto político y territorio" (Universidad de Antioquia, Medellín-Colombia, 2012) 
cia política. En este sentido, hablar de formación es hablar de una ética del reconocimiento, que se ofrece mediante el lenguaje, el trabajo y la interacción; este es un despliegue que se puede ver como sucesión y simultaneidad de momentos y que puede designar como constitución del sujeto (Vargas, 2007, p. 24). Para la especificidad de la FC dicha constitución del sujeto no es otra que su constitución como sujeto político.

En este orden de ideas, la FC es el proceso de formación de la subjetividad política, es la creación de condiciones de posibilidad para que el ciudadano (re)construya el proyecto político que desde luego trasciende a la institución escolar. En otras palabras, la FC es el proceso de constitución del ciudadano bajo ciertos ideales dados por el proyecto político. Se entiende entonces que la FC es auto-reconocimiento, no de manera individual sino en la interdependencia con los demás. Hay pues una mutua interdependencia en cuyo campo se forma la subjetividad política. Se establece así la correlación sujeto político (ciudadano) y proyecto político, en la cual hay una relación dialéctica en la que el ciudadano forma el proyecto político y el proyecto político forma al ciudadano.

Es necesario resaltar que no hay discurso de FC sin sujeto político, es decir, en el discurso de la FC el ciudadano no es prescindible y, en ese sentido, la pregunta ¿qué ciudadano se está formando?, es trascendental. En la FC están presentes y en tensión unos ideales subjetivos de ciudadanía, por lo tanto en la interacción y en el juego de las subjetividades hay una disposición presente que lleva a que los otros sean como nosotros, es decir, hay una intención, a veces velada, a veces explícita de que se trata tanto de normalizar como homogeneizar a ciudadanos mediante igualación de un discurso.

Pero, ¿Qué papel juega el proyecto político en la formación ciudadana? Al respecto debe reconocerse que el propósito de consolidar la democracia, a veces con matices y sentidos políticos muy diferentes, es compartido por los organismos multilaterales, por los gobiernos en sus diferentes niveles territoriales, por muchas ONG y demás actores sociales involucrados con el desarrollo, lo cual, dicho de otra forma, lleva a reconocer que ya nadie propone públicamente y no hay proyecto político, de izquierda o de derecha, que proponga que se deba limitar la democracia o impedir su desarrollo. Ese discurso, ahora hegemónico, se ha vertido en un sinnúmero de planes, programas y proyectos que pueden ser entendidos como procesos de innovación democrática, de ampliación del campo de la política y construcción de la ciudadanía, los cuales, según Evelina Dagnino, son experiencias que están resignificando la idea misma de democracia (2006, p. 15) ya que hay "una gran disputa de proyectos politicos que, usando los mismos conceptos y apelando a discursos parecidos, son de hecho completamente distintos". Ella se refiere, por un lado, al proyecto democrático-participativo, y de otro, al proyecto neoliberal de privatización de amplias área de las políticas públicas que se acompaña de un discurso participacionista y de revaloración simbólica de la sociedad civil, entendida como tercer sector (Dagnino, 2006, p. 16).

En ese sentido, un proyecto político alude a "construcciones simbólicas que mantienen relaciones cruciales con el campo de la politica y con culturas políticas particulares. Los actores que formulan y difunden los proyectos politicos expresan, por un lado, un aprendizaje normativo e impulsan nuevos principios culturales; $y$ por otro, con frecuencia reproducen también, especialmente en sus prácticas concretas, peculiares combinaciones de culturas politicas que muestran la coexistencia y la tensión entre los nuevos y viejos principios culturales" (Dagnino, 2006, p. 32). Lo anterior implica, en nuestra perspectiva, que el proyecto político es la gestión del territorio desde la perspectiva de la formación ciudadana, esto es, la dimensión políticapedagógica del territorio. 
Sin embargo, dicha resignificación de la idea de democracia en el seno de la disputa de los diferentes proyectos políticos no se visualiza fácilmente por el uso y abuso de las mismas nociones para referirse a la consolidación de la democracia. Incluso, lo que se evidencia muchas veces es un vaciamiento del sentido político de los diferentes proyectos políticos desde la óptica de los ciudadanos. Es común pues, que las políticas públicas, los planes y los programas que encarnan los proyectos políticos usen nociones comunes como "ampliar la participación", "lograr el desarrollo", "mejorar los niveles de equidad", "convivencia en paz", "fortalecer las organizaciones sociales", "generar capital social", "fortalecer el tejido social" o "formar en ciudadanía"; las cuales, generalmente, no tienen mayor problematización y sirven por igual para cualquier proyecto político. Esta situación ha sido señalada por Dagnino como una "confluencia perversa" (2002, p. 10) que oscurece las diferencias, la cual se puede definir por el encuentro entre los "proyectos democratizantes que se formaron en la resistencia contra los regimenes autoritarios y continuaron en la búsqueda del avance democrático y, los proyectos neoliberales que se instalaron con diferentes ritmos y cronologías, desde fines de los años 80. La perversidad se localiza en que, apuntando en direcciones opuestas y hasta antagónicas, ambos proyectos politicos utilizan un discurso y nociones comunes y reclaman una sociedad civil activa y propositiva" (Dagnino 2004, p. 14). En realidad estos proyectos políticos tienen sentidos muy distintos pero esta confluencia perversa obscurece las diferencias, homogeniza los matices y reduce los antagonismos (Panfichi, 2007).

Parafraseando a Milton Santos, el proyecto político se configura como un sistema de FC, en el que los programas y las políticas, como los analizados, tienen una solidaridad técnica, como formas perfeccionadas de interdependencia funcional (Silveira, 2011) para la reproducción política del mismo proyecto político y de la concepción del territorio que conlleva. El proyecto político como sistema de acción, en la medida en que tiene mayor posicionamiento y se configuran como hegemonía sobre el territorio, va centralizando y unificando cada vez más a la FC, que actúa con mayor precisión como una técnica, no sobre los objetos del territorio sino sobre las acciones del territorio.

Ahora, si se tiene en cuenta que los proyectos políticos afirman una relación entre las acciones y los imaginarios, los cuales se entienden en el vínculo indisoluble entre política y cultura y, en esa medida, entre política y educación, el reto es comprender cómo se comporta esa relación en un territorio concreto, es decir, cómo se gestiona el territorio desde la FC. Se trata de comprender dicha relación, teniendo en cuenta que las prácticas y las estrategias de acción política expresan, movilizan y producen significados que llegan a integrar matrices culturales más amplias relacionadas con la construcción de la esfera pública (Arendt, 1993). Consecuentemente, esa relación política y educación, es posible de ser analizada en los procesos de formación ciudadana, que son entendidos como procesos que buscan configurar determinado tipo de ciudadano y de esfera pública, en tanto proyecto politico. Por eso se puede plantear que los procesos de formación ciudadana son intenciones político educativas que buscan constituir un sujeto con imaginarios y prácticas en relación con lo público, consecuente con la lógica del proyecto político con el que se relaciona.

Desde esta perspectiva, se identifica que en todo proyecto educativo hay una apuesta formal o tácita de formación política, que terminan reforzándose mutuamente. Es decir, los proyectos políticos se reproducen sociológicamente mediante los procesos de formación ciudadana que éste auspicia y fomenta y, de manera inversa, los procesos de formación ciudadana toman su sentido (valores, principios, etc.) del proyecto político del cual son emanados.

Con Pierre Bourdieu se puede plantear la formación como constitución del sentido, subjetivamente experimentado, con procesos de reproducción simbólica que acontecen en la sociedad y que 
posibilitan, en unos casos o determinan en otros, al sujeto y al ciudadano. Esta perspectiva sociológica permite analizar los efectos de la producción de la subjetividad política: el sujeto -como ciudadano- no es un sí, en sí, diríamos, no nace se construye, por eso es una expresión de la época y de las estructuras culturales, es decir, permite llevar a cabo la comprensión de las agencias, dispositivos y mecanismos de producción de subjetividad.

Para la comprensión de la formación en la perspectiva mencionada se debe relacionar con el campo intelectual, ya que éste no solo se refiere a los procesos de formación del sujeto sino también a los procesos de formación de la cultura, entendida ésta en su referencia a los sistemas de control simbólico, dentro de las comunidades de discurso. En este sentido es posible precisar que la formación es un enlace entre el sujeto y la sociedad, y la formación ciudadana es el enlace específica entre el ciudadano y el proyecto político.

De manera complementaria desde la perspectiva de Hannah Arendt, más que aun carácter social, la formación ciudadana atiende precisamente a un carácter político por cuanto fluye en el "entre nos" en el que toman parte las paradojas de unir y separar a los seres humanos y de hacerlos conscientes de su igualdad y de su singularidad, más que el logro de un resultado orientado por un perfil, la formación ciudadana es un proceso permanente de aprendizaje que no está agenciado ni determinado por una institución particular, sino que está conformado por una trama de aprendizajes que se dan en todos los espacios de aparición (dentro de los que se incluye a la institución escolar) y que escapan a procesos de objetivación tal y como lo pretenden las denominadas competencias ciudadanas.

Así, la formación ciudadana, y sus expresión política, las subjetividades, es posible de ser comprendida como discurso, el cual, conceptualmente es entendido como una formación de sentido (de significación), relacional y diferencial que depende pero no queda determinada por sus condiciones de producción (que algunos ubican como contexto), que no posee una esencia ni fundamento que no sea histórica y espacial, y que es condición de posibilidad de la constitución del sujeto (Buenfil, 2006). En ese sentido, las subjetividades políticas son las expresiones de la formación y la constitución del sujeto político.

\section{EL TERRITORIO COMO POSIBILIDAD PARA LA FORMACIÓN CIUDADANA}

El proyecto político del territorio no se reduce a estrategias de actuación política en el sentido estricto, por ejemplo sobre la forma de lograr la FC y gestionar el territorio, sino que expresa, vehicula y produce significados que integran matrices culturales más amplias. Los distintos proyectos políticos, al mismo tiempo que se anclan en configuraciones culturales existentes, también elaboran e introducen nuevos elementos, tensionando y transformando el repertorio cultural de la sociedad.

Antes de plantear la relación de la Fc con el territorio, se debe hacer un acercamiento teórico al territorio, para la cual se retoma la concepción de Milton Santos y María Laura Silveira. Para Santos el espacio geográfico se entiende como un conjunto indisoluble, solidario y contradictorio de sistemas de objetos y sistemas de acciones, mediados por las normas (Santos, 1996). Dado que "no hay producción que no sea producción del espacio" y, asimismo, "la forma de vida del hombre es el proceso de creación del espacio" (M. Santos, 1995, p. 81), "lo que interesa discutir es, entonces, el territorio usado, sinónimo de espacio geográfico" (M. Santos; M. L. Silveira, 2001, p. 20). A cada período histórico le corresponde un medio geográfico específico, inherente a cada etapa del proceso de modernización, 
que no se expresa de manera sincrónica y homogénea en todos los países y regiones.

Cada territorio se articula de forma desigual al proceso de globalización, incorporando de modo diferencial y selectivo los "datos centrales del período histórico vigente", los cuales "derivan en transformaciones de los objetos, de las acciones, en fin, en el modo de producción. A ese proceso estamos llamando modernización" (M. L. Silveira, 1999, p. 22), en el cual la FC es clave para lograr la hegemonía del proyecto político. La modernidad surge en tanto "corte metodológico de la llegada permanente, a los lugares, de los vectores del mundo. De alli proviene la importancia de referirnos a las modernidades en plural, porque cada época es definida por las respectivas modernizaciones” (M. L. Silveira, 1999, p. 22). Lo que se evidencia es que una nueva modernidad se impuso a escala mundial, sustentada en tres procesos fundamentales: la presencia de un sistema técnico único -el capitalismo-, la existencia de una unicidad temporal -o convergencia de los momentos- a escala planetaria, y la producción de un motor unificado global, vinculado a la generación y apropiación mundial de la plusvalía. Esas son las bases del medio técnico-científico-informacional. El mundo se torna así una referencia constante para cada subespacio, cualquiera sea su extensión o importancia relativa.

Mientras que los espacios de la racionalidad, en virtud de su papel hegemónico o hegemonizado en el proceso espacial -según sea el caso-, regulan u obedecen los designios de la modernización, todas las situaciones geográficas que expresan la contra-racionalidad resultan definidas "por su incapacidad de subordinación completa a las racionalidades dominantes, ya que no disponen de los medios para tener acceso a la modernidad material contemporánea" (M. Santos, 2000, p. 246). Mientras que los espacios de la contra-racionalidad rechazan a la racionalidad hegemónica, los espacios de la racionalidad se someten a los designios de ésta, cuando no participan de su control.

Para Santos, la construcción de la globalización más humana supone un cambio histórico que debe provenir de un movimiento de abajo hacia arriba con el protagonismo de los lugares, es decir, de las personas que viven en los lugares de países subdesarrollados, esto es proyectos políticos locales ${ }^{1}$ Para el logro de este cambio hay una tarea: "la elaboración de un nuevo discurso, capaz de desmitificar la competitividad y el consumo y de atenuar, si no deshacer, la confusión de los espiritus"(Santos, 2004, p. 48).

El espacio es una posibilidad de nuevas realidades sociales, y es aquí donde él nos plantea la importancia de la política, entendida como "el arte de pensar los cambios y de crear las condiciones para tornarlas efectivas [...] Transformadas en situaciones promisorias" (p. 17). Eso implica comprender lo que el lugar realmente es: el lugar es en donde surge en primera instancia la relación del sujeto con el espacio, donde comienza su apropiación y significación, y es allí donde se concretan las instituciones y las formas organizadas de la vida social. El lugar, más que un objeto en sí, se refiere a áreas discretas pero variables en las que están localizados los objetos que dan sentido, se relacionan con las acciones, es decir, es lo que Santos denominó "Nuestro próximo", donde se [...] superponen dialécticamente el eje de las sucesiones, que transmiten los tiempos externos de las escalas superiores y el eje de los tiempos internos, que es el eje de las coexistencias, donde todo se funde, enlazando definitivamente las nociones y las realidades de espacio y tiempo" (Santos, 2000, p. 274).

El lugar, donde se verifican los proyectos políticos locales, es el espacio del orden cotidiano

1 Este aspecto fue presentado de manera ampliada en un capítulo de libro. Ver: Pimienta, Alejandro (2009) La globalización y el lugar de la ciudadanía: una reflexión a propósito de Milton Santos. En García y Aramburo (eds). Universos Sociespaciales. Procedencias y destinos. Bogotá: Siglo del hombre. 
compartido entre las más diversas personas, empresas e instituciones, por lo cual la cooperación y el conflicto son la base de la vida en común. Debido a que cada uno ejerce una acción propia, la vida social se individualiza; y debido a que la contigüidad es creadora de comunión, la política se territorializa, con la confrontación entre organización y espontaneidad. El lugar es el marco de una referencia pragmática del mundo, del cual le vienen solicitaciones y órdenes precisas de acciones condicionadas, pero es también el escenario insustituible de las pasiones humanas, responsables, a través de la acción comunicativa, por las más diversas manifestaciones de la espontaneidad y la creatividad (Santos, 2000, p. 274).

Se enfatiza así, que el lugar es un espacio de significación en el que se configuran las interacciones sociales y, en ese sentido, el lugar produce sujetos locales entendidos como agentes que pertenecen a una comunidad situada, inmersos en sus redes de relaciones. El lugar produce conocimiento local y órdenes locales que se pueden oponer dialécticamente a lo general o lo global, tal como lo plantea Santos cuando afirma que [...] se constituyen, paralelamente, una razón global y una razón local que en cada lugar se superponen y, en un proceso dialéctico, tanto se asocian como se contraponen. El lugar se enfrenta al Mundo, pero también lo afronta en virtud de su propio orden (Santos, 2000, p. 284).

Por tanto, en lo local se dan especificidades que pueden ser muy diferentes o incluso contrapuestas de otras que no son posibles de comprender abstractamente ni desde lo regional, nacional o global. En ese sentido, el lugar, el proyecto político local, es esperanza porque no se deja homogeneizar y en él siempre surgen órdenes contra hegemónicos y representa la posibilidad constante de la dialéctica porque aunque existan variables hegemónicas del periodo, que son un presente invasor, éste es ubicuo y nunca se realiza completamente, a eso se antepone otro presente localizado, que también es pasado objetivado en las formas sociales (Santos, 2004, p. 94): el lugar es el espacio de las prácticas y, como dice Santos, "No hacemos nada hoy que no sea a partir de los objetos que nos rodean" (Santos, 2000, p. 273).

El futuro no es apocalíptico pues constantemente hay órdenes locales emergentes en proyectos políticos de resistencia, y en la medida en que éstos coexisten pueden conformar una solidaridad orgánica y una solidaridad horizontal que crean racionalidades horizontales (contra racionalidades en relación con las racionalidades hegemónicas), es decir, "formas de convivencia y de regulación creadas a partir del propio territorio" (Santos, 2004, p. 90). La relación dialéctica entre verticalidades y horizontalidades garantizará siempre la existencia del lugar, es decir, los órdenes locales alternos desde los cuales se puede construir la ciudadanía: la ciudadanía del lugar o, mejor aún, las ciudadanías locales, para aludir a esos órdenes que se construyen en las horizontalidades siempre en relación dialéctica con las verticalidades propias de la globalización. Y en ese sentido, como el lugar -lo local - es a su vez, y a su modo, el mundo, lo reproduce de modo específico y, por tanto, los lugares y sus órdenes locales "son singulares, pero también globales, manifestaciones de la totalidad-mundo, de la cual son formas particulares" (p. 92).

Los anteriores planteamientos permiten relacionar de manera mucho más clara la relación del territorio con la FC. En ese sentido, se deja ver en lo planteado como ciudadanías locales, son ciudadanías de la totalidad-mundo o local-globales. Las ciudadanías locales son para la acción (con intención), es decir, sobrepasan su dimensión normativa, son praxis que por su condición crítica pueden ser constructoras de órdenes contrahegemónicos. La intención, entonces, es central en el análisis de la formación, pues el lugar no produce las ciudadanías locales automáticamente. Es necesaria la conciencia del lugar y la conciencia emancipatoria frente a las hegemonías implanta- 
das por el mercado, es decir, se construyen a partir del reconocimiento de lo propio, del lugar y su producto: lo local, pero sobre una base crítica. La posibilidad más fructífera de resignificar el lugar es considerando lo cotidiano como una dimensión de la realidad social que, para ser interpretada, necesita que sean aprehendidas las relaciones intersubjetivas que la caracterizan. De eso se ocupa Santos en la cuarta parte de su obra cumbre La naturaleza del espacio, denominada "La fuerza del lugar" (2000). Allí plantea que un elemento crucial en la producción de la intersubjetividad es la comunicación como actividad simbólica, y que esta producción es un proceso en el que entran en juego diversas interpretaciones de lo existente, en la que entran en tensión las ideas de "universalidad" o "totalidad" con las ideas del lugar. El lugar es el espacio de la proximidad social, lo cual para Santos configura múltiples relaciones sociales, incluso la identidad, la diversidad o la conciencia.

Santos (2000) también argumenta que vivimos en un tiempo de cambios y de movilidad, por lo que los hombres cambian de lugar como turistas o inmigrantes, lo que significa dejar una cultura heredada por otra, convirtiendo al lugar nuevo en sede de una alienación. Sin embargo, no se pierde la noción de residencia y de realidad, es decir, sigue habitando. Ese cambio constante, mutación de territorialidades, no es visto como una pérdida sino como una ventaja. La reinserción consciente a la vida local o global es una constante que depende cada vez menos de la experiencia y más del descubrimiento, por lo que se necesita del ejercicio constante de repensar y estar en estado de alerta.

A lo largo de su obra Santos se pregunta por la acción globalizada, a lo que responde que el mundo es un conjunto de posibilidades cuya efectividad depende de las oportunidades ofrecidas por los lugares. El territorio termina siendo la gran mediación entre el mundo y la sociedad nacional y local. En ese sentido, aunque el orden global busca imponer una única racionalidad en todos los lugares, éstos responden según los diversos modos de su propia racionalidad, es decir, cada lugar es al mismo tiempo objeto de razón global y razón local, relacionados dialécticamente.

El reto es, mediante la FC, construir una globalización más humana, en la que las personas sean lo más importante y no el mercado, y donde las personas sean más que simples consumidores y se realicen como ciudadanos por la participación con conciencia en lo público, y aporten a una sociedad más justa, equitativa y solidaria. Ese cambio requiere de intención, es decir, de formación ciudadana en todos los ámbitos sociales, lo cual pasa, según Santos, por la producción de un nuevo discurso, de una nueva metanarrativa, de un nuevo y gran relato (Santos, 2004, p. 22).

La construcción de ciudadanías locales es una intención política que puede ser entendida como un proceso de formación ciudadana relacionada con un determinado proyecto político, lo cual para Santos está relacionado con una metamorfosis que lleve a pensar en la producción local como una comprensión progresiva del mundo y del lugar, con la producción local de imágenes, discursos, filosofías, "junto a la elaboración de un nuevo ethos y de nuevas ideologías y nuevas creencias políticas, amparadas en la resurrección de la idea y de la práctica de la solidaridad" (Santos, 2004, p. 135), es decir, es un proceso social de toma de conciencia.

\section{REFLEXIONES FINALES PARA LA ESCUELA}

La investigación sobre FC desde la relación con los proyectos políticos y el territorio es una posibilidad para abordar la enseñanza de la geografía en tanto se pregunta por la intención pedagógica de dicha enseñanza. Por ejemplo, se pueden asuntos tales como la incidencia del docente, como sujeto político, en la formación de los estudiantes. De la misma manera, se pregunta por la concepción 
de territorio que tanto docentes como estudiante se representan, y cómo esa concepción influye en la formación ciudadana. También es posible que esta perspectiva aporte a la investigación en didáctica de la geografía, pues puede propiciar prácticas y estrategias didácticas contextualizadas, liberadoras y significativas en tanto el docente sea consciente de su rol como sujeto político y reconozca el sentido de la FC, y de esa manera reconozca que su acción no sólo permite el conocimiento del territorio sino que influye en la formación de las subjetividades políticas.

Algunos de los aspectos más relevantes a tener en cuenta es en la relación planteada es el uso del territorio, su implicación en la construcción del territorio desde la perspectiva política y teleológica, el deber ser del territorio usado, el cual, incluye a todos los actores y no sólo al Estado. La FC es una producción espacial y territorial porque a la vez que se deriva del territorio usado aporta a rehacerlo, teniendo en cuenta que el territorio usado se entiende como "el territorio heredado y el territorio rehaciéndose a partir de un conjunto interdependiente y conflictivo de objetos técnicos, normas y acciones. Por ese motivo, el territorio usado acoge tanto acciones pasadas, cristalizadas en objetos y normas, como las acciones presentes, desarrollándose en el instante presente" (Silveira, 2011, p.3).

La FC no se presenta en el territorio de manera espontanea, ingenua o aislada, sino que adquiere su sentido en el marco del proyecto político y se objetiva en acciones educativas, como las de la escuela o en los ámbitos de la educación no formal, es decir, la relación de la FC con el territorio se puede observar mediada por el proyecto político, lo cual le da el sentido y la articulación coherente a las acciones que aparentemente pueden estar aisladas.

Desde esta perspectiva, la FC es el motor del proyecto político y se observa como técnicas y normas, entendidas como formas de hacer, que transforman la comprensión y la gestión del territorio. Así, el proyecto político aporta a que la organización normativa sea funcional a la división territorial del trabajo hegemónica y a algunos grupos económicos y políticos, que tendrán voz para priorizar ciertas ideas políticas, determinadas actividades económicas y nuevas o renovadas jerarquías regionales (Silveira, 2011); Además, las técnicas y normas que expresan el proyecto político y a la FC, suponen una relación más cercana para los sujetos, y es la formación de sus discursos políticos.

Ahora bien, para comprender la FC desde esta perspectiva se hacen necesarias acciones diversas, comenzando por una actualización de los currículos universitarios de formación de licenciados en educación y normalistas superiores para que comprendan el sentido de la FC y su relación con el territorio, de manera que puedan darle un tratamiento pedagógico a esta problemática y así crear proyectos didácticos coherentes con su discurso. En dicha actualización, propiciar que los maestros en formación vean las potencialidades pedagógicas y analíticas del territorio para la FC. Es en esta línea que se justifican los procesos de formación continua para maestros en ejercicio en los que desarrollen proyectos pedagógicos de FC que incluyan al re-conocimiento del territorio como el elemento significativo que le da sentido político a la FC.

De manera complementaria, en los proyectos pedagógicos de FC que los maestros lideren en sus instituciones deben identificar que el sentido de la FC que están implementando está dado por el orden y por la configuración que le den a la triada ciudadanía-educación y territorio, es decir, los maestros deben hacer de la FC un proceso consciente y sistemático para lograr que se sobrepase la simple instrucción y conocimiento del territorio.

Por supuesto que un camino para que la enseñanza de la geografía sea significativa es aprove- 
chando el conocimiento de la ciudad y lo local (Pimienta, 2008) como un potencial para la FC en proyectos pedagógicos con los estudiantes, es decir, hacer de la ciudad un medio didáctico, un objeto de enseñanza y un escenario propicio para el encuentro de saberes cotidianos, el saber escolar y los saberes expertos (Pulgarín, 2010). La ciudad como medio didáctico debe ser debe partir de la microescala, el barrio y vereda, como espacio más significativo de los sujetos.

En el desarrollo de los proyectos pedagógicos que buscan la FC desde la escuela se debe reconocer que el estudiante se forma en todos los ámbitos de la vida social, por lo cual el fin del proyecto debe ser que el estudiante comprenda y tenga un discernimiento del sentido político del mundo que lo rodea (Pimienta, 2010).

La ciudad y el territorio como una mediación pedagógica para la FC también emerge como una posibilidad para la integración curricular (Pulgarín, 2007), es decir, la FC no debe pensarse como una cátedra sino como un proceso sistemático e intencionado con diversidad de estrategias didácticas. Por eso, se deben promover ejercicios pedagógicos que descentren el proceso de educativo del aula y de la institución para re-conocer el territorio del barrio y los escenarios urbanos, para lo cual se deben aprovechar las salidas pedagógicas, como procesos intencionados que reflexión colectiva (Pimienta, 2008).

Para el desarrollo de los proyectos pedagógicos de FC en la escuela, que como se dijo son intencionados y en los que el maestro debe discernir la relación ciudadanía, educación y territorio, el maestro debe acudir a su saber fundante, la pedagogía., en los que resultan particularmente productivos los aportes de la pedagogía crítica con autores como Henry Giroux y Paulo Freire (Pimienta, 2007 y 2008), es decir, la concepción pedagógica de una propuesta que forme en ciudadanía crítica y activa, debe acercarse a la pedagogía crítica y social, ya que la primera busca recuperar una existencia concreta de la relación pedagógica como espacio de construcción de significados en tanto reconoce la diversidad cultural y por ende la diversidad de construcciones simbólicas, imaginarios y cosmogonías. Este enfoque apunta al fortalecimiento cultural de los sujetos individuales y colectivos, y en ese sentido se podría entender también la necesidad del conocimiento del territorio local. Su finalidad es permitir, en nuestro caso, una formación ciudadana, en la cual además de brindar conocimientos y entrenamiento en obtención de habilidades se permita la comprensión, adaptación y transformación del medio local. En nuestra concepción, este enfoque permite vincular la formación ciudadana y los proyectos políticos.

Se trata de fundamentar una propuesta pedagógica que parta de comprender los mecanismos ideológicos que penetran la conciencia y las prácticas de las sociedades contemporáneas. A ese respecto, Giroux, llama la atención sobre la ética de la racionalidad positivista que excluye la autocrítica y se constituye en una forma de hegemonía ideológica que términos políticos deviene en un conservadurismo que lo hace sostén ideológico del statu quo (1999).

Valga decir que la categoría crítica, se refiere al interés de crear conscientemente teoría para la crítica y al desarrollo de un discurso para la transformación y emancipación social que supere las condiciones hegemónicas impuestas por el capitalismo. En otras palabras, la categoría crítica se encuentra en el pensamiento que hace la distinción entre lo que es y lo que debería ser.

Esta perspectiva de la pedagogía crítica social, a nivel latinoamericano ha sido desarrollada por Paulo Freire. Bien lo mencionó en este sentido Giroux, cuando se refirió en estos términos: "Situán- 
dose en el espacio que media entre lo político y lo posible, Paulo Freire pasó la mayor parte de su vida trabajando con la convicción de que merece la pena luchar por lo elementos radicales de la democracia, de que la educación crítica es un elemento básico del cambio social y de que nuestra forma de pensar sobre la política es inseparable de nuestra forma de entender el mundo, el poder y la vida moral que aspiramos llevar" (Giroux 1998, p. 42). Se reivindica, que somos ciudadanos, con las prácticas e imaginarios que conlleva, en la medida de nuestra comprensión del mundo, por lo que la práctica transformadora solo tiene sentido con base en la conciencia de nuestra situación.

Finalmente, resaltar del legado freiriano su concepción de que lo pedagógico es político, por lo cual la práctica pedagógica es una práctica política, que como tal, cualquiera que sea el propósito explícito de una intención formativa, a la vez, es una práctica de formación ciudadana. El reto, apoyado en Freire, es reconocer y develar las prácticas formativas supuestamente neutrales que terminan formando en ciudadanías bancarias y disciplinadas de las condiciones hegemónicas y, por supuesto, fundamentar y transformar las prácticas educativas explicitando las intenciones de formación de ciudadanías liberadoras. Por eso la intención formativa en la acción pedagógica debe radicar en brindar elementos de juicio crítico a las personas para que reconozcan su situación y la distancia

que hay entre esa realidad y la fábula que se plantean sobre eso, para que así realmente tenga la esperanza de lograr su libertad.

\section{BIBLIOGRAFÍA}

Arendt. H. (1997) ¿Qué es la política? Paidós. España.

Arendt, H. (2004) Los orígenes del totalitarismo. Alianza Editorial. Taurus. México.

Buenfil, R.N (2006) Lógicas y sentidos inscritos en la subjetividad: políticas educativas y pistas para su transformación. En: Vitar, Ana (coord.) Políticas de Educación. Razones de una pasión. Buenos Aires: Miño y Dávila, OEI.

Dagnino, E; Alberto O y Panfichi (coords) (2006) La disputa por construcción democrática en América Latina . México: FCE, CIESAS

Bourdieu, P. (1999). Meditaciones Pascalianas. Barcelona: Anagrama

Freire, P. (1972). Educación liberadora.Medellín, Colombia: Editorial Pr isma

Freire, P. (2001). Política y educación. México: Siglo XXI

Giroux, H. (1997). Los Profesores Como Intelectuales: Hacia Una Pedagogía Crítica Del Aprendizaje. Barcelona. Paidós.

Giroux, Henry. (2001). Cultura, Política Y Práctica Educativa. Barcelona Editorial Graó

Laclau, E. (2005) La razón populista. Argentina: Fondo de Cultura Económica

Mouffe, Ch, (2007) En torno a lo político. Fondo de Cultura Económica 
Pimienta, A (2008) El Conocimiento de la localidad para la integración curricular. En: En Pulgarín Silva, Raquel et.al (Comp) Estrategias que invitan a la integración curricular. Medellín: Secretaría de Educación de Antioquia

Pimienta, A (2007) El reto de la educación: Formar en ciudadanías locales para el cambio social. Memorias del $50^{\circ}$ Congreso Latinoamericano y Caribeño de Ciencias Sociales de FLACSO, Quito: FLACSO

Pimienta, A y Ospina G (2008) La ciudad como escenario pedagógico: el conocimiento de lo local para la formación ciudadana. Medellín: Revista Textos Vol 6 Nro. 11. Universidad Pontificia Bolivariana.

Pimienta, A (2009) La globalización y el lugar de la ciudadanía: una reflexión a propósito de Milton Santos. En García y Aramburo (eds). Universos Sociespaciales. Procedencias y destinos. Bogotá: Siglo del hombre

Pimienta, A (2010). La "Ciudad Educadora" y el Presupuesto Participativo en Medellín. ¿qué ciudad(anía) enseña? En: Boletim Paulista da Geografía. Abril, Nro. 89. Sao Paulo: Universidad de Sao Paulo.

Pulgarín, R (2008). Hacia la integración del plan de área de ciencias naturales y sociales desde el estudio del territorio y la formación en competencias. En: Hacia el desarrollo de una actitud científica en la escuela desde la enseñanza de las ciencias, memorias, pp. 33-54, Medellín, Colombia, Gobernación de Antioquia.

Pulgarín, R. (2010). La educación geográfica un compromiso en la enseñanza de las ciencias. Propuesta de formación docente para el oriente antioqueño En: Revista Uni-plridiversidad, Facultad de Educación, Universidad de Antioquia. Vol.10 No.3.

Santos, Milton (1998). O espaço do cidadão. $4^{a}$ edición, Nóbel. São Paulo-Brasil.

Santos, Milton (2000). La naturaleza del espacio: Técnica y tiempo, razón y emoción. Ediciones Ariel Geografía, Barcelona-España.

Santos, Milton (2000). La naturaleza del espacio: Técnica y tiempo, razón y emoción. Ediciones Ariel Geografía, Barcelona-España.

Santos, M (2004). Por otra globalización: del pensamiento único a la conciencia universal. Bogotá, Convenio Andrés Bello.

Silveira, María Laura (2011) Territorio y ciudadanía: reflexiones en tiempos de globalización. En: Uni-pluri/versidad, Universidad de Antioquia, (Medellin) Vol. 11, No. 03

Vargas, G (et. al.). (2007). Formación y Subjetividad. Bogotá: Universidad Pedagógica 